\title{
6
}

\section{Co-creation with Companies: A Means to Enhance Societal Impact of University Researchers?}

\section{Kirsi Pulkkinen and Antti Hautamäki}

\section{Introduction: Problems and Solutions in Co-creation}

Exploring the meaning of co-creation follows the idea of the entrepreneurial university (Etzkowitz et al. 2008; Clarke 1998). This resembles the idea of searching innovative approaches and embracing renewal of practices to solve problems, without turning universities into business (Lyytinen 2018). Yet, rather than focusing on the variety of possibilities universities could offer, the discussions have centered on the regional and economic impacts (Trencher et al. 2014). The market logic has dominated discussions on the development of universities and their role in society, and largely ignored that the positive economic impact of universities are based on long-standing research efforts that follow the science logic (Berman 2012).

K. Pulkkinen $(\bowtie)$

University of Lapland, Rovaniemi, Finland

e-mail: Kirsi.pulkkinen@ulapland.fi

A. Hautamäki

University of Jyväskylä, Jyväskylä, Finland

(C) The Author(s) 2019 
This chapter explores the following research question: how does cocreation between universities and companies enhance the responsibility of universities? The responsibility of universities manifests itself on issues how universities help companies and public organizations to adopt and apply new knowledge in solving local and global wicked problems. Co-creation is an effective way to meet this challenge. We are guided by an interest to understand what elements are needed for co-creation to occur, and why and how this form of collaboration is pursued in universities. We approach the research question through an experimental project and place it in a broader context of the changing academic working environment. While the experiment provides a micro-level view into the thinking of researchers and businesses, it allows us to explore the sense-making (Weick and Sutcliffe 2005) of two groups of participants in a live setting.

The major reason for developing co-creation models is the failure of a linear model of knowledge transfer (Trencher et al. 2014). Conventional academic dissemination is one-sided and ignores the capability of knowledge users to understand and apply the knowledge. Hence, interest has grown toward identifying more effective ways to improve adaptation of new knowledge during the knowledge creation process. This entails a double-change in mindsets: firstly, that participation in knowledge creation supports learning by promoting sharing and, secondly, that in order to access the knowledge of others all actors (including academic researchers) need to open up to have discussions already during the process of knowledge creation. Co-creation is a process where the lines between knowledge producers and knowledge users become muddled, and they discuss and work together in solving shared concrete problems. This is the essence of co-creation.

\section{Co-creation in the Evolution of Science-Society Relations}

Co-creation is a reflection of European evolution of science-society relations. The status of researchers and universities as the dominant producers and disseminators of knowledge has changed gradually while consultancy companies, think tanks and so on have entered the field. The goal of the modern university to spread knowledge in society has trans- 
formed, but continues to connect to the attainment of educated citizenship (Delanty 2001). Mode 1 introduced the linear understanding of technology transfer (Regeer and Bunders 2009; Gibbons et al. 1994). Moving to a co-productive mode 2 presented a more constitutive change, as the operating models of both science and other institutions began a transformation toward joint knowledge creation (Nowotny et al. 2003). Universities started to be envisioned as societal actors among others and the separation of knowledge creators and problem solvers blurred.

In the current situation, societal interaction is increasingly realized through collaboration in a mutually beneficial process (e.g. see Prahalad and Ramaswamy 2004; Ramaswamy and Gouillart 2010; Trencher et al. 2014). The change is seen also in policy developments, such as changing EU's funding instruments from "Science and Society" to "Science in Society" and further to "Science with and for Society" and has pushed to formalize the new working environment. Governmental steering functions are increasingly used to legitimize the existence of universities and use of public funds (Välimaa 2004). As with governance, a policy convergence process seems to appear also in relation to the pressure to increase societal interaction (Pulkkinen et al. 2019). Governments are changing the discourse, rules and policies of knowledge transfer and interaction. These are adapted to local level as the concepts that govern our understanding of science-society relations change, leading ultimately to behavioral changes in research communities (Moisio 2018). The Finnish Strategic Research Council funding instrument (Aarrevaara and Pulkkinen 2016) is a case in point.

Societal interaction is part of the social contract and accountability of universities (de Jong et al. 2016). However, the internal tensions of science communities and the contradictory expectations posed on universities also surface. Open science and the push to commercialize research have raised questions about intellectual property rights and the need to verify scientific quality through expose to counter-argument and conventional peer review (Nowotny et al. 2003). This balancing act between research integrity (Banks 2018) and economics-driven interaction is reality for researchers. Policy-makers and university managers have marketed co-creation with external arguments but failed to tackle the practical need for tools to manage the contradiction. Understanding the 
dynamics and underlying assumptions of research-company co-creation has thus become a crucial element in the process of developing working mechanisms for researchers, universities and companies alike.

\section{Co-creation}

We approach co-creation as a transformative path that consists of several steps. The aims of the collaborators define which format is relevant and feasible in a given context. In this chapter, we focus on bridging cocreation, which aims at creating connections between two sets of differently thinking and acting participants who share certain interests. Bridging co-creation produces solution proposals for problems that are identified in cooperation between equals rather than in a master-servant setting. This could continue to experimental co-creation or co-development, which aims to find solutions to a company's problem by experimenting with options. Co-research refers to research that is conducted by a university and company together, and aims to create new knowledge. The work is then more abstract in nature and less focused on solving a particular problem (Hautamäki et al. 2018).

Co-creation is not only collaboration but particularly a mutual learning process (Guile 2010; Hakkarainen et al. 2004). There are no external stakeholders in the co-creating group of participants. Instead, all participants have a stake in the identification and framing of a problem as well as the knowledge creation process. Their stakes vary due to different personal backgrounds and professional roles, but the weight of their stakes is of equal value. This is akin to communities of practice that agree on their shared code of excellence through direct collaboration (Brown and Duguid 2001). Managing the boundary work with science ethical principles intact requires, however, that researchers recognize high-quality science from low-quality and non-science (Vuolanto 2014).

\section{Problem and Solution in Co-creation}

Co-creation is analogous to the open innovation paradigm (Chesbrough 2003). The problems to be solved are not defined beforehand by one 
party, but rather identified through discussions. Co-creation provides a way to tackle unstructured problems, which are difficult to specify and require unconventional approaches. Knowledge production is tightly intertwined with problem solving, making scientific knowledge function side by side with social and experiential knowledge (Regeer and Bunders 2009). Co-creative problem solving thus follows a Schumpeterian idea that solutions are innovations by combining existing know-how and resources (Schumpeter 1934) and build a coherent system of complementary knowledge. The interaction process and the learning open innovation entails is itself a valuable solution as it leads the participants on a path (Spaapen and van Drooge 2011). The solution may not be measurable with indicators. A solution is not expected to be a prototype of a product or service, but rather steps that are necessary to reach a concrete solution. They can also be properly defined and well-targeted questions for new collaborative projects, seeds for an organizational transformation or new applications of existing data.

\section{Conceptual Framework: Dialogue as a Tool for Sharing and Creating Knowledge}

We approach co-creation as a phenomenon in a rapidly changing research environment. University institutions and individual researchers operate between multiple pressures (Stilgoe et al. 2013) and respond to external pressure. One of these is connected to finding ways to interact proactively with other actors, and managing to create new knowledge-based value. Responsibility is not portrayed in the number of interactions but rather their quality. As such, responsibility implies actions beyond communication and focuses on creating processes where universities tackle societal challenges. They do not only produce new knowledge but also participate in finding solutions.

Co-creation provides an avenue for this as it is inherently interspecialist interaction (Karvonen 2014) where researchers need to uphold high scientific quality and integrity, and develop their skillset in order to remain relevant. Inter-specialist interaction is not just academic expertise but rather created through action, which is based on extensive knowledge 
within a particular field. As such it is a dimension of co-generated learning and knowledge creation (Klev and Levin 2012), but with an essential difference in understanding of inclusion. While co-generated learning and knowledge creation differentiate between insiders and outsiders, our approach to co-creation considers such a separation superfluous and harmful to the building of shared visions. Instead, all stakeholders (Kazadi et al. 2016) are insiders in a shared process. Experts from different fields communicate ideas to each other with the intention of learning, but their language, interaction styles and perspectives differ. Participants are required to acknowledge their own and others' strengths and limitations, while being aware of the differences in use of language. Moving beyond this communicative challenge and further to the process of mixing different expertise to create new knowledge is where co-creative practices serve a purpose.

The SECI model of Nonaka et al. (Nonaka and Konno 1998; Nonaka et al. 2001) provides a structure for conceptualizing co-creation in the academic world. This model (see Fig. 6.1) focuses on converging tacit and explicit knowledge dimensions. Tacit knowledge is internalized in experiences, values and ideals and difficult to formalize, which makes it hard to communicate to others explicitly in words or graphs. It is experiential knowledge, something we know but cannot verbalize (Polanyi 1966). Explicit knowledge, on the other hand, is expressed in words and numbers. It can be communicated through data, formulae, manuals and so on and "be readily transmitted between individuals formally and systematically” (Nonaka and Konno 1998, 42).

In the SECI model, knowledge creation starts with the socialization (S) of discussants and their tacit knowledge. Because tacit knowledge is highly context-specific and difficult to verbalize, its transfer to others requires shared experiences, joint activities and physical proximity (Nonaka et al. 2001). During the externalization (E) phase, the individual participants fuse their ideas to form a new dynamic whole. Participants articulate their own and interpret others' tacit knowledge, which has been translated to understandable forms using metaphors, examples, diagrams and so on (Nonaka et al. 2001). These are utilized to enable reflection between the participants as tacit knowledge is activated, marked as "dialogue" in Fig. 6.1. 


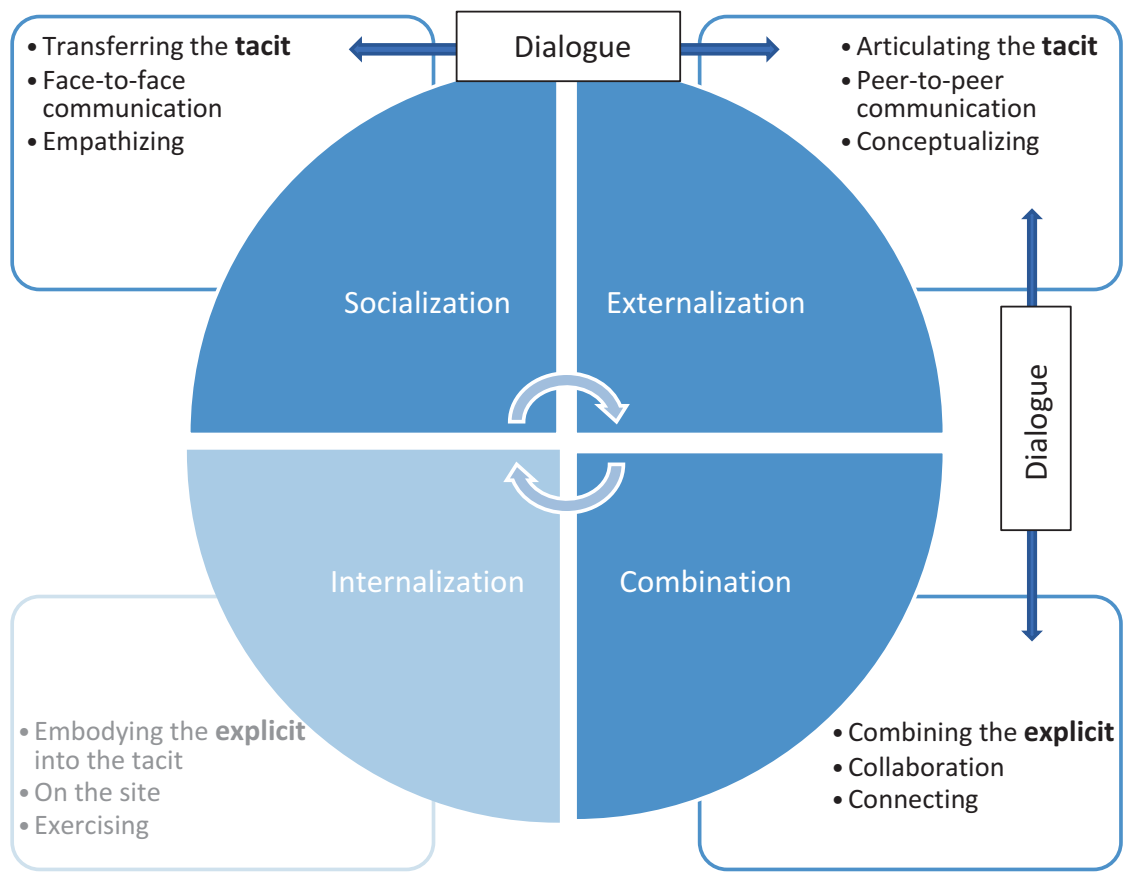

Fig. 6.1 The SECl model, adapted from Nonaka and Konno (1998) and Nonaka et al. (2001)

In the combination $(\mathrm{C})$ phase, the pools of explicit knowledge start to converge into more complex and systematic explicit knowledge. Participants communicate them through documents, meetings and conversations. In the process of sorting, combining and categorizing existing knowledge, the participants reconfigure it to create new knowledge (Nonaka and Konno 1998). The logic is akin to innovative knowledge communities (IKC) developed by Hakkarainen et al. (2004) whose purpose is to create new knowledge by combining different types of expertise into a new whole. Finally, in the internalization (I) phase, the new explicit knowledge is embodied into tacit knowledge. It transforms through a process where individuals share new knowledge throughout an organization, and use it to broaden and reframe tacit knowledge and understanding (Nonaka et al. 2001). Seen in the context of the three types of co-creation described in section "Co-creation in the Evolution of 
Science-Society Relations", this phase extends beyond bridging co-creation and is thus outside the scope of this study.

In order to apply the SECI model into university-company co-creation, an understanding of the difficulties of bridging scientific disciplines is needed. Discussion in the academic world rests on critiquing the work of others and testing them through counter-arguments. The conventional peer-review process follows this format, which Myra Strober (Strober 2010) calls the "doubting game." Here competition and rivalry between researchers, their frameworks and results form the basis. This makes trust an inherently difficult feature to gain (Elbow 1973). While this style of discussion is justified in an academic context consisting of experts from similar fields, it is ill-suited for interdisciplinary and multi-professional contexts. To achieve constructive and solution-oriented discussion, the "believing game" is needed (Strober 2010). In such a setting, participants follow and develop, rather than criticize the ideas and approaches that others present in dialogue. In order to build trust and gain new understanding, participants need to have confidence in others' expertise and show this in their communication by allowing the crossing of (disciplinary) boundaries (Hakkarainen et al. 2004). Practicing the believing game for a longer period may lead the participant to discover new creative potential and avenues of thought that they would not have found in their conventional setting (Strober 2010). This, in turn, facilitates a move toward connecting their own specialized, disciplinary knowledge to that of others, for example, by forming and testing hypotheses (Hakkarainen et al. 2004). A synthesis that follows is a result of the mixing of separate worlds. It is not likely to be found without verbalization of thoughts and trust in other discussants.

The essence of Strober's interdisciplinary discussion format ties closely with Nonaka's SECI model, leaning heavily on articulation of hidden knowledge and value structures. Furthermore, both are built on the premise of dialogue (Alhanen 2013; Bohm 1996) between different types of expertise. They aim at understanding others rather than convincing them of the primacy of one's own argument, and rest on the belief that the mixing of different types of expertise has the potential to produce creative solutions. 


\section{Data and Method}

The data for this chapter is derived from an experimental project that took place in 2017 and was funded by the Finnish agency for innovation Tekes, now Business Finland. The project is here referred to as COHU ("CO-creation model of Helsinki University").

The project was led by the Research Services' Business Collaboration Team at the University of Helsinki. In addition, the core team included Helsinki Innovation Services as well as an experienced external facilitator. The team was transdisciplinary and consisted of experts with backgrounds in biology, physics, engineering, anthropology, philosophy and political science. As the project was part of a larger Innovation Scout (iScout) program aiming at supporting research-based innovation, its target was to develop and pilot a functional model for co-creation. In order to make the model sustainable, the project also included a research component focusing on two things in particular: (1) what are the core characteristics that differentiate co-creation from conventional collaboration, and (2) which formats or tools work in researcher-company co-creation.

The selection of participants for the project was done with purposive sampling in order to allow for the experimental character of the project. This project did not aim at generalizability but followed co-creation principles (Regeer and Bunders 2009) where participants are purposefully selected from different backgrounds to complement existing knowledge (Hakkarainen et al. 2004). Five companies and seven post-doc or associate professor-level researchers from the humanities and social sciences (SSH) at the University of Helsinki participated in the project. SSH fields were selected because there is less tradition of business collaboration and because they play an integral role in solving complex issues related to wicked problems. The researcher participants represented communications, philosophy, sociology, social psychology and social policy and were selected to represent a broad spectrum of views: while some were positive or neutral to business collaboration, there were also those who held prejudged, critical views. The companies were selected through negotiations with diverse actors in the broad networks of the facilitator. The companies ranged from small start-ups to multinational corporations, and represented the fields of housing, IT, law, health and the metal industry. 
The project ran six facilitated half-day workshops that were held fortnightly during March-May 2017. Each workshop began with an informal breakfast, followed by an intensive three-hour session where participants sat in a circle with no physical obstacles between them. Participants were requested to refrain from using laptops and other digital devices.

The facilitator of the process was a professor emeritus of innovation studies who, in addition to academic expertise, had experience of working in companies and public foundations. His background and extensive experience from different kinds of developing processes gave him authority as well as capabilities to facilitate the dialogue. As part of the workshop facilitation, he wrote a report for all companies about the problem they presented and the results reached in the dialogue process.

Two researchers, an anthropologist and a political scientist, specialized in societal interaction of science, observed the project with a combination of participatory action research principles (Reason and Bradbury 2008). They recorded the workshop discussions without participating in the discussions of the sessions. In the workshops, attention was given to the verbal communication as well as body language, gestures, tones and style of speaking.

The workshops followed a structure, despite the experimental nature of the project. Discussions were held with the facilitator and the project team between the workshops to evaluate the situation and to adjust plans. Adjustments concerned the order in which cases were discussed, length and style of presentation, and constructive ways of managing conflicts. The team made decisions to adjust plans collectively.

Representatives of companies initially proposed problems for discussion but the final formulation was defined jointly by all participants. This helped start the discussions but allowed the problems to be formulated so that they were deemed interesting and relevant for all. This key premise was made clear to participants prior to the workshops, and it was reiterated at the beginning of the workshop series. They worked toward defining potential solutions that in most cases were intangible in character or service-centered. A dialogue method (e.g. Bohm 1996; Senge 1990) based on equality was used in the workshop sessions. The idea of the "believing game" (Strober 2010) was explained in the first workshop. 
A systematic content analysis was performed with the data, using the NVivo software. A conceptual hierarchy was formed based on combining the SECI model with Strober's interdisciplinary conversations model. The analysis followed four main dimensions which were based on Strober's model, with the role of facilitation being treated as a cross-cutting issue under each. The dimensions listed below were then placed in the different phases of the SECI model in order to follow progression of co-creation through the process.

- Defining goals, interests and visions

- Shared language

- Defining forms of collaboration

- Working logic

\section{Analysis}

In the workshop, the expectations of all participants-including the project team-were openly presented to boost transparency and trust. Each came to the experiment as professionals in their own fields. Combining researchers and companies whose fields did not match was an intentional choice aimed at allowing the discussions to focus on building understanding rather than sticking to familiar jargon. The researcher participants received no remuneration for their efforts and companies paid no fees. Their involvement was voluntary, but all participants committed to all workshops. In order to support the confidentiality of discussions and required trust between participants, a non-disclosure agreement was signed.

\section{Defining Goals, Interests and Visions}

There was a specific effort during the first two workshops to build an environment of equality. Companies presented initial problem ideas, while researchers put forth a brief portrayal of their academic back- 
ground. While most followed standard, even stereotypical styles, one skillfully broke the pattern using story-telling techniques to capture others' attention. Beginning with "communication is the telling of a love story" (researcher R1), she defied the expectation of a conventional researcher and managed to lure all participants to listen as she explained what this meant. She talked in layman's terms through live examples. The move followed throughout the workshop sessions as an example of surprise made possible by open minds of the listeners, and the courage of the presenter to break habits. It set the stage for exploring uniting angles. Yet, the speech also embodied the early sharing which remained removed from others, and resembled thinking aloud to themselves rather than actually delving into dialogue.

Strober's "believing game" was set as an overall wish for all discussions and a premise for interaction. By opening up to new perspectives, the participants began to understand the limitations of their original ones. Demands of the process itself provided a concrete enough link, and so stepping to unfamiliar territory and facing prejudices connected the participants before any issues of substance. Realizing the vastness that lay beyond their own perspectives seemed to inspire participants, especially company representatives, to share their own interests and visions. The tension that first existed in the room was eased once the participants dared expose their own preconceptions through light-hearted jokes.

One thing that disturbed the discussion in the beginning were unexpected prejudices. The way people related to those who came from another background. It opened up little by little when we got to understand each other's thoughts. But this is a problem in all new teams. Here the format was different. No table except for the first session. An empty space in between, it had to be filled with something. We had to create something to get away. (Company, C1)

Development of the discussions followed Strober's pattern of interdisciplinarity. Trust is a prerequisite for productive conversations (Strober 2010), but this accentuated the facilitator's role in two ways. Firstly, the facilitator acts as a guarantor of equality between participants, regardless of their background. Trust in this fairness precedes trust between participants. Secondly, in order to avoid development of restraining factions, 
the facilitator must be able to pay attention to the complex feelings of participants. The SECI socialization phase stresses a similar focus on empathy. In COHU, reoccurring confusion was created by co-facilitators unclear roles. This led to inconsistencies in their reactions in discussions as they revealed lack of understanding for different speech community rules by demanding styles closer to their own. The main facilitator's skill in mediating such situations, however, helped restore and strengthen trust in the process and highlighted the importance of facilitation.

Regarding the goals for cooperation with researchers, companies emphasized the role of scientific knowledge challenging their usual thinking frames: companies were not after "quick-fixes" to concrete problems. They sought partnerships with researchers to find solution paths to wicked problems, not everyday problems.

If we need solutions to everyday problems, we turn to consultancy companies. Companies don't want to steer universities to become consultancies. We want cooperation based on researchers' research work. All we want is to work with researchers on what they're already doing. It's what they know. (Company, C2)

Researchers, why do you hold back? There're think tanks, we need to develop do tanks. We need talk tanks so we can really talk about issues. (Company, C3)

For the researchers involved in the COHU project, co-creation was a way of showing they are willing to face the claims of responsibility, also for their own sake.

As a researcher you feel, well, a little dead at times, because research work is so slow and you can't concentrate on it because the university processes take so much time. This has been lovely, there's been time to think. I feel like I've found whole new empirical dimensions to my research. (Researcher, R1)

Both companies and researchers communicated visions of wanting to serve a purpose. While in the beginning these were separate and based strongly on assumptions, the visions began to converge through the facilitator's efforts to uphold a proper structure. As Strober (2010) notes, a specific commitment is needed for exploration of syntheses. It was clearly 
the role of the facilitator to make room for observation and the voicing of all ideas. This meant that presentations were shortened so that enough time was available for reflection in the group.

Deeper dialogue emerged as the participants could verbalize their underlying hesitations and confusions. This made their value structures more visible. Participants started to reflect more critically, which led to questioning the basis of the experimentation itself.

Collaboration between researchers and those outside academic circles is in a wild state. The formats that break borders of science are muddled. What is the kind of cooperation where the focus is on co-creation? The terminology of cocreation is so confusing and diverse that you can't grab it. (Researcher, R3)

Strober (2010), following March (1991), emphasizes the importance of distinguishing between exploration and exploitation as a means to balance portfolios. In tackling the efforts to find shared visions, this distinction came to fore. Exploitation is action that utilizes existing knowledge, while exploration is action that takes peoples outside that, which is already known to look for something new. The effort meant that participants needed to look at their own perspectives through the lenses of others. This is in line with the SECI externation phase; it is important to recognize and analyze new perspectives and to perceive their value.

I didn't always think about where the ideas came from. It is good that there's enough diversity. If all the companies were similar we'd go straightforwardly somewhere. When we're really lost, we're actually getting somewhere. There's no pondering about the destination. If someone thinks they know where the finish line is it's too easy to just head straight there. With so many types of experts here the discussion was balanced. We took the time to think about possibilities. (Company, C1)

Throwing ideas led the participants to realize they weren't as far from each other in their thinking as they thought. This became apparent only after the participants had started to discuss the basic assumptions behind their interests, visions and fears, that is, able to articulate their tacit knowledge in the externalization phase. 


\section{Shared Language}

Prior to the workshop sessions, the project team had expectations on use of concepts and professional jargon. During the first workshop, it was clarified that participants should all pay attention to avoiding use of jargon as it splits rather than unites the group. Efforts were instead needed to use non-technical language, yet without losing or hiding the professional expertise. The team, however, realized during the workshops that they had themselves fallen victim to generally held notions of companies not being interested in hearing conceptual talk. Somewhat surprisingly, companies were positive about the coining of new terms, and requested more specific and pointed use of words.

Why would we automatically dilute the specific language? Why would we need to create a new language to discuss these things when we already have a language that can manage complexity — the scientific one. (Company, C1)

Another pattern emerged in relation to discussing internal issues of relevance only to similar actors. This had the same effect as using jargon but in a more explicit sense.

A small, slightly disturbing, issue is the occasionally occurring academic talk that bypasses companies. I understand that there's too little space to have such big discussions across scientific borders. Universities are like big corporations where you run into surprising new dimensions and want to discuss them. But in the future when you include companies in co-creation, it's worth considering whether falling to academic talk here is a good idea. (Company, C5)

Several researcher participants followed similar patterns of thought. This was interesting as concepts lie at the heart of the scientific communities. Managing a multitude of concepts within the open-minded process played a major role in the planning of the COHU dialogue process, despite several science communication guides urging researchers to avoid conceptual talk. Instead of pushing them apart, the use of concepts seemed to bind the participants together. Being clear about the meanings of terms or phrases encouraged participants to challenge others, while 
giving an opportunity to take a deeper look at the tacit processes of their own professions. The issue of using concepts to tackle problems appeared when discussion turned to the pace at which (consultancy) companies brand new terminology.

The operative logic is different. Consultants needed to create revenue, and coining new concepts serves this purpose. Good concepts continue to live. I agree with [company C4], communication and operative actions must be in line. (Researcher, R7)

An opinion is just an opinion. Science brings perspective to discussions that companies would otherwise be lost in. We need that perspective. (Company, C5)

If it's a good process it'll be adopted and used. It makes all the difference how the concept is brought in. (Company, C1)

As the discussion around problems unfolded, the debate about use and meaning of concepts such as what constitutes a problem became more specific. The pieces of explicit knowledge brought forward by individual participants were being molded to create new knowledge, shared understandings of the concepts and why they were so complex, following the principles of the SECI combination phase. While some continued to defend their original standpoints, many of the participants realized that they could only provide a partial view of the issue and that the other parts were needed to find feasible solutions. Strober (2010) discusses such patterns from the viewpoint of creativity. To increase creativity, it's necessary for discussants to diversify the idea categories, not the quantity of ideas. By producing more categories through the utilization of multiple perspectives, it is possible to generate more flexible and original ideas and solutions.

One of the key roles of the facilitator was to ensure that spoken language was understandable to all. However, the more tedious and central task consisted of getting participants to understand how the others think: their assumptions, methods, evaluating and reporting "truth," that is, their habits of mind (Strober 2010) or tacit knowledge particularly in the socialization-externalization interface of the SECI model. As shown in 
the quotes above, language is strongly embedded in socio-linguistic systems and the underlying speech communities. The COHU facilitator nurtured even negative viewpoints, including toward co-creation/design/ development and so on, in order to support the translation between the different linguistic systems. This demanded tolerance for frustration in discussions but resulted in collective realizations on how others made sense of issues and sought solutions.

\section{Defining Forms of Collaboration}

Co-creation means solving problems in cooperation with people with diverse backgrounds and different competence profiles. The problem can be a simple concern that needs to be clarified or solved, a phenomenon, occurrence, task, product and so forth. At the beginning of the COHU project the problems could be vague and complex, such as unsuccessful communication or dysfunctional division of work in the company. The problems could also be a new phenomenon, such as the impact of artificial intelligence on specialists' work. Some problems were extremely challenging, for example, measuring service impact or the role of emotions in digital communication.

Over the course of the workshops, the problem definitions changed in several ways. A participant who had presented a solution and was in need of a problem ended up realizing that what seemed an obvious solution would instead entail multiple ethical problems that the company could not accept. Another participant frustrated by personnel management issues realized that the problem was instead in the communication style that unintentionally signaled disrespect toward the employees. Participants stated that the reason they could come to such realizations was the completely different perspectives brought by experts, which they would normally not have thought to consult. For a social psychologist, the dialogue sessions had been an eye opener to new possibilities.

I've noticed that my own research fields are relevant to companies. Shared emotions can be utilized in a group to develop internal solidarity. There could be practical applications for these. This knowledge could actually have other uses than just writing. (Researcher R4) 
Researchers' expectations of and responses to co-creation vary. Some worry about losing their scientific autonomy and integrity, and about becoming mere commissioned researchers who serve the needs of nonacademic groups. Others are frustrated over not feeling appreciated as professionals for their research efforts. However, many also found opportunities in being challenged.

Managing the change requires broader skills, action and impact from universities. There's a huge risk involved if researchers only focus on publication when the probability of getting a permanent position is so small. Globally we recognize the political pressure towards universities and researchers. It's up to us how we react to it. We risk running ourselves into a corner. (Researcher, R1)

Scientific curiosity and the process of interaction drive this group. They have an interest in broadening their skillset, which resembles the thinking of life-long learning. For them co-creation provides new employment opportunities. They view co-creation as a function that supports also their "purely" scientific endeavors as interaction with non-academics challenges their mindsets and pushes their scientific thinking forward. From a knowledge production perspective, the difference reflects both the externalization and the combination phase of the SECI model. As noted by Strober (2010), the clashes are understandable and finding common ground is only possible once participants can move beyond the externalization and reflect on the meanings that others bring to the table.

I'm interested in how services are built. [Company C5] problem helped me structure my interest and specify what I want to do next. I approach research problems through thinking what I can methodologically learn from them. I now got concrete ideas about the problems that companies have. The feeling of academic detachment is eased. (Researcher R6)

The forms of collaboration also tie to what can be gained financially from the cooperation. For companies, it seemed obvious that they should pay for the services that co-creative collaboration can provide for them. It was even understood as a way to show that universities value the intellectual property they possess. For companies, problems and solutions entail economic, technological and commercial aspects. They realize the 
potential data, equipment and infrastructure they can provide to research processes. For researchers, the opportunities were only partly visible at the start of the process, but the exchange of thoughts helped clarify the situation. The "rules" of collaboration were clearly in line with the SECI combination phase where discussions were concrete and highlighted the value of their own and others' knowledge and work. It seemed that in order to collaborate properly, both companies and researchers wanted the other party also to recognize their own value so as to strengthen the connection in a balanced manner.

I got lots of concreteness from the companies. Data from [Company C3], enthusiasm. We've already started. From [Company C1] an entirely new idea to pedagogical development, which is also very conceptual and theoretical. In listening to you I understood how a particular model could be supplemented. I've now pushed that forward. It's possible this idea never would've surfaced without these discussions. (Researcher R1)

Finding genuine new solutions in cooperation with like-minded people is demanding. With participants coming from different organizations and disciplines, issues appearing as "self-evident" needed to be unraveled and clarified. By playing "the believing game," the co-creation process managed to highlight deficiencies in existing operating methods and in alleged truths. This realization led to re-evaluations of the problems or finding new, unanticipated solutions as the participants began to converge their thinking in the combination phase. In the combination phase, the participants played "the believing game," as noted by Strober (2010) and Elbow (1973), to the fullest as they tried to understand the interpretations that were foreign to themselves but implied opportunities to succeed.

\section{Working Logic}

Collective learning proved necessary for the knowledge exchange and the SECI process to function. It occurred systematically in response to conflicts and clashes in the discussions. At times, these originated among researchers, for example, on the meaning of a concept or an academic 
working habit. This confused companies but they seemed to try to follow the thread and built bridges. The "believing game" proved tricky to uphold, but discussants fought to keep dialogue going, with coherent support by the facilitator.

So many insignificant administrative events. A lot of consultancy talk. You create a nice conceptual construction for the audience and then lead them to recognize something there. The foundations or substance is never elaborated. This is tricky for researchers. (Researcher R3)

I recognise this from the company world. A lot of speeches that are accepted as opinions, but no one explains why things are the way they are claimed to be. The substance and meaning is missing. (Company C5)

What is inside and what outside? I'm intrigued. Is there a fundamental difference in the working logic? (Company $\mathrm{C} 1$ )

The clashes exacerbated differences in underlying value and ideal structures. Critically minded researchers could frustrate others but managed to push for the biggest breakthroughs. In the end, the dialogues brought researchers critical to co-creation to realize that companies were not trying to dismantle science ethical principles, but rather looking for ways to find mutually functional working models.

I feel like I'm from the wrong field. It seems the most I can do is to help question concepts. (Researcher R3)

The main facilitator interrupts, offering support. "But this is an academic virtue."

I would so like to get my hands dirty and do more than just question. It's nice to hear that others have gained more. I could perhaps offer something to solve your [project team's] problems, that's my expertise. I could be of use there. (Researcher R3)

Advancing research-company co-creation is only possible if universities understand the logic of co-creation and, in particular, the coupling to 
scientifically viable arguments. The COHU project showed that instead of an external demand, researchers need evidence of how co-creation fits with the scientific community and supports career development. There was a shared curiosity to understand the dynamics of co-creation in order to be able to apply them in teaching and research consortia. Similarly, there was an interest to understand how facilitation works, with the specific intention of developing skills on facilitation of societally linked knowledge production. This result follows the learning curve from the conventional academic "doubting game" to a more cooperatively minded "believing game." Over the length of the workshops, researchers and company representatives had learned to understand the others' thinking patterns better through dialogue. Their conceptualization of problems and potential solutions had evolved from a superficial communication of own thoughts to peer communication in the externalization phase and further to explicating concrete collaboration in the combination phase on their own merit.

\section{Concluding Discussion}

Returning to the research question "how does co-creation between universities and companies enhance the responsibility of universities?" we find that co-creation is a goal-oriented tool - not an end result. It is a tool to demonstrate responsibility in a manner that cuts across all functions at universities. It is not merely a part of the so-called third mission but rather a feature that is, or could be, integrated into all parts of action, be they teaching, research, management or societal relations. First and foremost, co-creation that serves a purpose in a university setting is a cross-cutting operational mode, which facilitates learning individually as well as between actors.

In the piloted bridging co-creation model, dialogue was considered a tool for co-creation, not the aim as such. The real target was co-creative knowledge production between researchers and companies, and approaching co-creation with the SECI model allowed an exploration into subprocesses of knowledge production. The analysis shows that dialogue holds a core position in the learning that constitutes the essence of cocreation (Fig. 6.2). Its role is highlighted especially in the intersections 
where tacit knowledge is externalized to open discussion and complementary knowledge from different participants is combined into new knowledge (innovations and solutions). In bridging co-creation, externalization and combination phases dominate, that is, the more social levels of the process, where also the sharing of experience (and skills) happens. It is also learning process, in which explicit knowledge is internalized at a personal level. These two last phases of SECI model are operating in full effect in co-development and co-research, where the interaction between researchers and companies is long-standing and intensive. All elements are present even in bridging co-creation.

Bridging co-creation between researchers and companies provides a limited outlook to co-creative options. However, analysis of the experiment showed that such a focused format already included the essential parts for productive co-creation: problem definition, composition of questions, perspectives, learning through exposure, the meaning of trust and reciprocity. The role of dialogue proved to be particularly essential in the enabling of several perspectives, building of trust between participants and reciprocity of sharing. These produce the central building blocks of the externalization and combination phases of the SECI model.

Socialization

Sharing experience

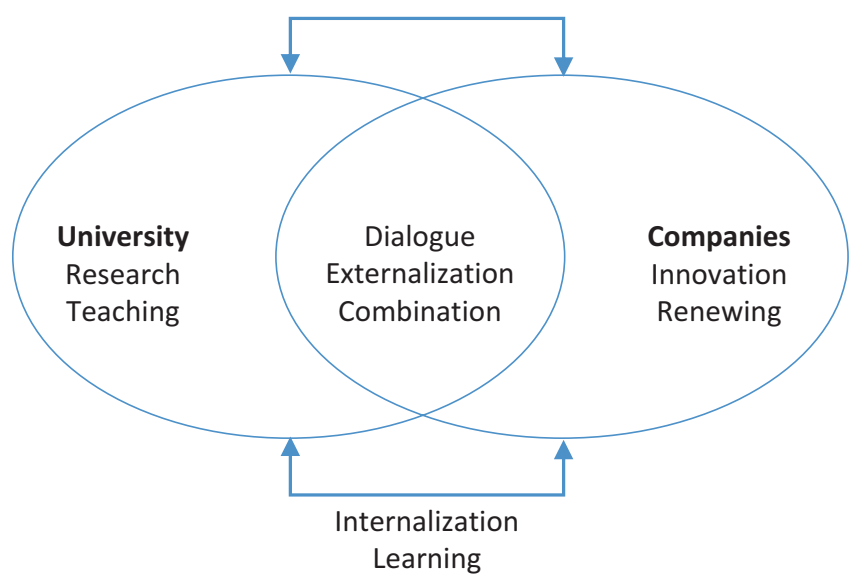

Fig. 6.2 The SECI Model in Co-creation 
This leaned strongly on the facilitator, who acted as a knowledge broker. As such, the facilitator performed translation tasks (Hakkarainen et al. 2004), in micro-format, as independent activities aimed at supporting knowledge production in a rapidly changing environment.

Bridging co-creation seems to lean on the idea of epistemic communities (Haas 1992). These consist of knowledge-driven actors who share similar goals, cognitive frameworks and an understanding of their roles in a system. Such communities exist in the academic as well as other expert contexts. It is in the meeting of these epistemic communities where new knowledge can emerge if suitable dynamics for co-creation exist. Understanding the importance of personal responsibility is a premise for the participants to be able to verbalize their tacit knowledge in a way that is understandable to discussants from other disciplines and professions. This is necessary to move from the externalization phase to the combination phase of the SECI model.

As with the centrality of dialogue in the same phases, the $\mathrm{COHU}$ project showed that the knowledge production process does not follow a straight path. Instead, it moves in multiple directions and builds opportunities for learning by allowing the participants to move between phases naturally and even simultaneously. Here, the role of an experienced, broadly trusted facilitator, who provides the necessary support structure for the goal-oriented process, is highlighted. The advancing of co-creative practices entails facilitation tasks (Regeer and Bunders 2009) which are generally not included in conventional research training. This has led to a need to develop capacity and competencies for facilitation that promotes credibility broadly.

While the COHU project used an external facilitator, it would not provide a sustainable or particularly responsible practice in the long run. In order to ensure that both scientific integrity and societal interaction are upheld, facilitation should be managed by the university in the long run. If the role was understood in a narrow sense as a communication issue, the risk of breaking science ethical principles could be jeopardized. Discussions about the meaning and importance of research integrity and researchers' virtues (Banks 2018) are necessary for the building of such trust. They include not only application of reliable methods of research but being curious and critically minded, conscientious, open, honest and 
willing to listen to other researchers. Researchers' personal epistemic responsibility is central in research and knowledge creation (Code 1987). If virtues and personalities of researchers are stressed, then integrity is a crucial issue in co-creation, also with companies. To uphold this, universities could invest in the development of facilitation skills as a form of specialization for researchers who have an interest in dynamic forms of knowledge production. Such training could also provide a skillset that boosts employability of researchers outside academia.

So, is co-creation a reflection of the responsible university? It is a way to implement and strengthen the societal responsibility of universities, a phenomenon that can build bridges and deepen the understanding of what makes universities unique institutions in society. However, it can also set the ideals of modern science (such as open science) on a crashcourse with the practices of business (e.g. IPR) (Stilgoe et al. 2013) if universities encourage the use of co-creation without considering its implications and preconditions. The engagement intensity of co-creation concretizes the clash of science and market logics (Berman 2012), and forces researchers to contextualize the meaning of research integrity in a new light. However, this should not only be seen as a threat but rather a chance to deepen the understanding of what the role of scientific research is in modern society. Sharing tacit and explicit knowledge with companies allows researchers to appreciate the practices that make their research work significant if they choose to create new, scientifically and societally valuable explicit knowledge jointly with, for example, companies. In the $\mathrm{COHU}$ project such crystallizations appeared through realizations that while universities have lost their dominant positions as producers of knowledge, they remain the most capable institutions to link needs of industries, public sectors and informed citizenship (Delanty 2001) in a systematic and analytical manner.

Finally, the COHU project provides practical lessons that warrant further investigation. The $\mathrm{COHU}$ project showed that company interests in co-creation with universities lies in gaining access to scientific knowledge. Companies are willing to trade their experiential and practice-related skills and data in order to build a mutually beneficial setting. The building of a safe and respectful context requires that rules for the bridging of different worlds are defined and meeting dynamics led (Haynes 2011). 
Essentially, what is needed are consultancy-skilled researchers who have expertise not only in their field of substance and recognizing the boundaries of science (Vuolanto 2014) but also in dialogical techniques.

Responsibility is not only about production of knowledge and "pouring" it on others. It can be a goal-oriented mix of problem and solutioncentered action. This is what makes co-creation meaningful for all participants. Co-creation is epistemic responsibility (Code 1987), that is, responsibility to scientific communities as well as to society. It is one way of applying the corporate social responsibility mode of thinking into a university environment. University citizenship responsibilities entail the furthering of shared societal goals, supporting societal development (including but not limited to the economic) and working for the common good. Co-creation is based on equality between participants, rather than a master-servant setting, and as such a platform for in-depth learning that has the ability to produce change.

Acknowledgments We would like to extend special thanks to Emmi Holm for her efforts in collecting the data from the COHU project, and for valuable discussions with the COHU project leader Dr. Maarit Haataja on the role of cocreation in university context and Dr. Leena Ripatti-Torniainen on the possibilities of co-creation in developing university pedagogics. A further thanks is owed to James Tommy Karlsen and Miren Larrea for valuable comments to an earlier version of this chapter. We also kindly acknowledge the generous iScout funding to the $\mathrm{COHU}$ project from former Tekes (now Business Finland), project number 4870/31/2016.

\section{References}

Aarrevaara, T., \& Pulkkinen, K. (2016). Societal Interaction of Science in Strategic Research Council Funded Projects. Project report for Public Engagement Innovations for Horizon 2020. Retrieved from https://pe2020.eu/wp-content/uploads/2014/02/Soc-interaction-at-SRC_160916_valmis.pdf.

Alhanen, K. (2013). John Deweyn kokemusfilosofia [The Experiential Philosophy of John Dewey]. Helsinki: Gaudeamus.

Banks, S. (2018). Cultivating Researcher INtegrity: Virtue-Based Approaches to Research Ethics. In N. Emmerich (Ed.), Virtue Ethics in the Condusct and Governance of Social Science Research (pp. 21-44). Emerald Publishing Limited. 
Berman, E. O. (2012). Creating the Market University. How Academic Science Became an Economic Engine. Princeton, NJ: Princeton University Press.

Bohm, D. (1996). On Dialogue. New York: Routledge.

Brown, J. S., \& Duguid, P. (2001). Knowledge and Organization: A Social-

Practice Perspective. Organization Science, 12(2), 198-213.

Chesbrough, H. (2003). Open Innovation, The New Imperative for Creating and Profiting from Technology. Boston, MA: Harvard Business School Press.

Clarke, B. R. (1998). Creating Entrepreneurial Universities: Organizational Pathways of Transformation. Oxford: Pergamon.

Code, L. (1987). Epistemic Responsibility. Hannover: University of New England. de Jong, S. P. L., Smit, J., \& van Drooge, L. (2016). Scientists' Response to Societal Impact Policy. Science and Public Policy, 43(1), 102-114.

Delanty, G. (2001). Challenging Knowledge. The University in the Knowledge Society. Buckingham: Open University Press.

Elbow, P. (1973). Writing Without Teachers. New York: Oxford University Press. Etzkowitz, H., Ranga, M., Benner, M., Guaranys, L., Maculan, A. M., \& Kneller, R. (2008). Pathways to the Entrepreneurial University: Towards a Global Convergence. Science and Public Policy, 35(9), 681-695. https://doi. org/10.3152/030234208X389701.

Gibbons, M., Limoges, C., Nowotny, H., Schwartzman, S., Scott, P., \& Trow, M. (1994). The New Production of Knowledge. London: Sage Publications.

Guile, D. (2010). The Learning Challenge of the Knowledge Economy. Rotterdam: Sense Publishers.

Haas, P. M. (1992). Epistemic Communities and International Policy Coordination. International Organization, 46(1), 1-35.

Hakkarainen, K., Palonen, T., Paavola, S., \& Lehtinen, E. (2004). Communities of Networked Expertise. Professional and Educational Perspectives. AmsterdamTokio: Elsevier.

Hautamäki, A., Haataja, M., Holm, E., Pulkkinen, K., \& Suni, T. (2018). Co-creation. A Guide to Enhancing the Collaboration Between Universities and Companies. Helsinki: University of Helsinki.

Haynes, C. (2011). Interdisciplinary Conversations: Challenging Habits of Thought (Review). The Journal of Higher Education, 82(6), 803-805.

Karvonen, E. (2014). Tiede tuottaa todellisuutta - Kenen etujen mukaan ja kuinka eettisesti? In R. Muhonen \& H.-M. Puuska (Eds.), Tutkimuksen kansallinen tehtävä (pp. 53-86). Tampere, Finland: Vastapaino.

Kazadi, K., Lievens, A., \& Mahr, D. (2016). Stakeholder Co-creation During the Innovation Process: Identifying Capabilities for Knowledge Creation Among Multiple Stakeholders. Journal of Business Research, 69(2), 525-540. 
Klev, R., \& Levin, M. (2012). Participative Transformation Learning and Development in Practising Change. Farnham: Gower.

Lyytinen, A. (2018). The Concept of the Entrepreneurial University for Analysing the Organisational Transformation of Higher Education Institutions. In E. Pekkola, J. Kivistö, V. Kohtamäki, Y. Cai, \& A. Lyytinen (Eds.), Theoretical and Methodological Perspectives on Higher Education Management and Transformation. An advanced reader for PhD students (pp. 105-118). Tampere: Tampere University Press.

March, J. G. (1991). Exploration and Exploitation in Organizational Learning. Organization Science, 2(1), 71-87.

Moisio, J. (2018). Policy Transfer in Higher Education Policy Formation. In E. Pekkola, J. Kivistö, V. Kohtamäki, Y. Cai, \& A. Lyytinen (Eds.), Theoretical and Methodological Perspectives on Higher Education Management and Transformation. An Advanced Reader for PhD Students (pp. 67-86). Tampere: Tampere University Press.

Nonaka, I., \& Konno, N. (1998). The Concept of "Ba". Building a Foundation for Knowledge Creation. California Management Review, 40(3), 40-54.

Nonaka, I., Konno, N., \& Toyama, R. (2001). Emergence of “Ba”. A Conceptual Framework for the Continuous and Self-Transcending Process of Knowledge Creation. In I. Nonaka \& T. Nishiguchi (Eds.), Knowledge Emergence (pp. 13-29). New York: Oxford University Press.

Nowotny, H., Scott, P., \& Gibbons, M. (2003). Introduction. 'Mode 2 Revisited: The New Production of Knowledge'. Minerva, 41, 179-194.

Polanyi, M. (1966). The Tacit Dimension. New York: Doubleday \& Company, Inc. Prahalad, C. K., \& Ramaswamy, V. (2004). Co-creation Experiences: The Next Practice in Value Creation. Journal of Interactive Marketing, 18(3), 5-14.

Pulkkinen, K., Timo Aarrevaara, T., Nordstrand Berg, L., Geschwind, L., Foss Hansen, H., Hernes, H., Kivistö, J., et al. (2019). Does It Really Matter? Assessing the Performance Effects of Changes in Leadership and Management Structures in Nordic Higher Education. In R. Pinheiro, L. Geschwind, H. F. Hansen, \& K. Pulkkinen (Eds.), Reforms, Organizational Change and Performance in Higher Education. A Comparative Account from the Nordic Countries (pp. 3-36). Cham: Palgrave Macmillan.

Ramaswamy, V., \& Gouillart, F. (2010). Building the Co-creative Enterprise. Harvard Business Review, Issue Oct 2010.

Reason, P., \& Bradbury, H. (Eds.). (2008). The Sage Handbook of Action Research: Participatory Inquiry and Practice. Thousand Oaks, CA: Sage. 
Regeer, B. J., \& Bunders, J. F. G. (2009). Knowledge Co-creation: Interaction Between Science and Society. Den Haag: RMNO.

Schumpeter, J. (1934). The Theory of Economic Development. Cambridge, MA: Harvard University Press.

Senge, P. M. (1990). The Fifth Discipline: The Art \& Practice of the Learning Organization. New York: Doubleday Business.

Spaapen, J., \& van Drooge, L. (2011). Introducing 'Productive Interactions' in Social Impact Assessment. Research Evaluation, 20(3), 211-218.

Stilgoe, J., Owen, R., \& Macnaghten, P. (2013). Developing a Framework for Responsible Innovation. Research Policy, 42, 1568-1580.

Strober, M. H. (2010). Interdisciplinary Conversations. Challenging Habits of Thought. Stanford, CA: Stanford University Press.

Trencher, G., Yarime, M., McCormick, K., Doll, C., Kraines, S., \& Kharrazi, A. (2014). Beyond the Third Mission: Exploring the Emerging University Function of Co-creation for Sustainability. Science and Public Policy, 41(2), 151-179.

Välimaa, J. (2004). Kolmas tehtävä korkeakoulutuksessa: tavoitteena joustavuus ja yhteistyö. In K. Kari, K. Erkki, K. Pirjo, L. Tarmo, N. Mika, \& J. Välimaa (Eds.), Yliopistojen kolmas tehtävä? (pp. 43-68). Helsinki, Finland: Sitra. Vuolanto, P. (2014). Hyvän tieteen määrittely ja rajanvetokiistat. In R. Muhonen \& H.-M. Puuska (Eds.), Tutkimuksen kansallinen tehtävä (pp. 259-270). Tampere: Vastapaino.

Weick, K. E., \& Sutcliffe, K. M. (2005). Organizing and the Process of Sensemaking. Organization Science, 16(4), 409-421.

Open Access This chapter is licensed under the terms of the Creative Commons Attribution 4.0 International License (http://creativecommons.org/licenses/ by/4.0/), which permits use, sharing, adaptation, distribution and reproduction in any medium or format, as long as you give appropriate credit to the original author(s) and the source, provide a link to the Creative Commons licence and indicate if changes were made.

The images or other third party material in this chapter are included in the chapter's Creative Commons licence, unless indicated otherwise in a credit line to the material. If material is not included in the chapter's Creative Commons licence and your intended use is not permitted by statutory regulation or exceeds the permitted use, you will need to obtain permission directly from the copyright holder.

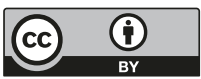

